\title{
CONVENÇÃO SOBRE A DIVERSIDADE BIOLÓGICA (CDB): A NECESSIDADE DA REVISÃO DO SEU TEXTO SUBSTITUINDO O TERMO “RECURSOS GENÉTICOS” POR “RECURSOS BIOLÓGICOS” NOS ARTS 1, 9, 15, 16 E 19
}

\author{
Vladimir Garcia Magalhães ${ }^{1}$
}

\begin{abstract}
RESUMO: O presente trabalho analisa o texto da Convenção sobre a Diversidade Biológica (CDB) e a necessidade de sua alteração, sugerindo nova redação para os artigos 1, 9, 15, 16 e 19, com a substituição nestes dispositivos, do termo recursos genéticos por recursos biológicos, de modo a incluir todas as demais moléculas biológicas de valor econômico e científico, real ou potencial, presentes na biodiversidade, principalmente no que se refere ao acesso e à repartição de benefícios, tendo em vista a salvaguarda dos interesses dos países em desenvolvimento ou subdesenvolvidos, detentores da maior parte da biodiversidade no planeta, via de regra países, extremamente vulneráveis, econômica e politicamente, nas relações internacionais com os países desenvolvidos.
\end{abstract}

PALAVRAS-CHAVE: Convenção sobre a Diversidade Biológica, biodiversidade, recursos genéticos, recursos biológicos

Convention on Biologic Diversity (CBD) - the need to review its text replacing the term "genetic resources" with "biologic resources" in articles 1, 15 and 19

\begin{abstract}
The present study analyses the text of the Convention on Biologic Diversity (CBD) and its need of amendment, and suggests a new wording for articles 1, 9, 15, 16 and 19, by replacing the term genetic resources with biologic resources in these provisions, in order to include all the remaining actual or potential biologic molecules of economic and scientific value, which are present in the biodiversity, mainly as regards the access and the sharing of the benefits, in view of the protection of the interests of developing or underdeveloped countries, which hold most of the planet's biodiversity, which as a rule of thumb are extremely economically and politically vulnerable countries, concerning the international relationships with developed countries.
\end{abstract}

KEY-WORDS: Convention on the Biological Diversity, biodiversity, genetic resources, biologic resources.

\footnotetext{
${ }^{1}$ Graduado em direito e biologia na Universidade de São Paulo (USP), mestre e doutor em direito pela Faculdade de Direito da Universidade de São Paulo (FADUSP). Professor de direito da Escola Superior de Direito Ambiental e Faculdade das Américas, advogado e consultor ambiental. Email: vlad@usp.br
} 


\section{Introdução}

A Convenção sobre a Diversidade Biológica (CDB) foi criada em decorrência do intenso debate que foi se formando, notadamente a partir dos anos 60, em relação ao meio ambiente e a sua proteção, assim como em relação a sua crescente importância política, legal e econômica (COSTA E SILVA, 1997, p.40).

O desenvolvimento industrial e a expansão das atividades econômicas das empresas dos países desenvolvidos para os países menos desenvolvidos e com meio ambiente mais preservado, foram fatores determinantes para o aumento do processo de destruição de vários ecossistemas muito importantes e expressivos no planeta, como as florestas tropicais. Paralelamente, o desenvolvimento das pesquisas científicas relacionadas ao meio ambiente permitiu entender e valorar melhor o significado dos ecossistemas e dos danos neles causados pela sociedade humana.

Essa crescente preocupação internacional em relação ao meio ambiente veio a ser formalizada no sistema da ONU, durante a Conferência das Nações Unidas sobre o Meio Ambiente Humano, realizada em Estocolmo entre 5 e 16 de junho de 1972.

Essa conferência elaborou um Plano de Ações para o Meio Ambiente que reorganizou todas as recomendações aprovadas pela conferência e uma Declaração sobre o Meio Ambiente Humano estabelecendo princípios gerais que embasavam a elaboração de mecanismos multilaterais necessários para a proteção do meio ambiente e para a criação de um sistema institucional que coordenasse ações e políticas conjuntas dos países para a proteção ambiental (COSTA E SILVA, 1997, p.40).

Devido à esta crescente preocupação internacional com o meio ambiente, uma resolução da ONU, ainda no ano de 1972, sugeriu o estabelecimento de um programa, dentro do sistema institucional da própria ONU, que coordenaria todas as atividades ambientais em âmbito nacional e internacional, assim como o desenvolvimento de instrumentos legais internacionais e leis modelos para serem adotadas pelos países, com o fim de implementar o Plano de Ações para o Meio Ambiente. Como conseqüência desses fatos, foi instituído formalmente pela ONU em 15 de dezembro de 1972, pela Resolução 2.997, o PNUMAPrograma das Nações Unidas para o Meio Ambiente.

Em 1992, entre os dias 3 e 14 de junho, foi realizada na cidade do Rio de Janeiro, no Brasil, a Conferência das Nações Unidas sobre o Meio Ambiente e o Desenvolvimento, 
também conhecida como Cúpula da Terra ou simplesmente ECO-92 (COSTA E SILVA, 1997, p.40).

Nesta conferência foram aprovadas a Declaração do Rio sobre Meio Ambiente e Desenvolvimento, a Agenda 21, a Declaração de Princípios sobre o Consenso Global no Manejo, Conservação e Desenvolvimento Sustentável de Todos os Tipos de Florestas, a Convenção sobre a Mudança Climática e finalmente, a Convenção sobre a Diversidade Biológica (CDB).

O Brasil assinou a CDB em 5 de junho de 1992, tornando-se Parte desta Convenção por meio do depósito do instrumento de ratificação em 28 de fevereiro de 1994, após sua aprovação interna pelo Decreto Legislativo $\mathrm{n}^{\circ} 2$ de 3 de fevereiro de 1994, o qual também aprovou a Agenda 21. A CDB foi promulgada no Brasil pelo Decreto 2.519, de 16 de março de 1998 sendo que em seu anexo se encontra o texto da CDB, em tradução oficial.

\section{Os metabólitos dos organismos}

Todo organismo produz metabólitos primários e secundários. Os primários são considerados essenciais para os organismos e estão relacionados ao seu crescimento e constituição biológica. São metabólitos primários os ácidos nucleicos (DNA e RNA), carboidratos, açúcares, aminoácidos e ácidos orgânicos.

O ácido desorribonucléico (DNA) constitui os genes que são o material genético dos seres vivos. Ele é sintetizado pelo metabolismo primário dos organismos e é formado por outras moléculas menores que são as bases nitrogenadas denominadas de nucleotídeos. Existem duas categorias dessas bases nitrogenadas no DNA, as bases do tipo purínico e as do tipo pirimídico. Existem quatro tipos: a adenina $(A)$ e a guanina $(\mathrm{G})$, são bases nitrogenadas purínicas; a timina $(\mathrm{T})$ e a citosina $(\mathrm{C})$ são bases nitrogenadas pirimídicas.

Todas vão se organizar em uma seqüência variável para constituir o DNA na forma de uma dupla hélice helicoidal, onde a adenina pareia com a timina e a guanina com a citosina (STRYER, 1979, p.557-566). As funções biológicas de um gene serão decorrência direta da seqüência específica de bases nitrogenadas que constituem esse gene. As seqüências dessas bases, portanto, variam de gene para gene e, por este motivo, as funções e produtos destes genes também variam. 
O ácido ribonucleico (RNA) é também uma macromolécula sintetizada pelo metabolismo primário dos organismos vivos, com as mesmas bases nitrogenadas purídicas e pirimídicas do DNA, exceto pela uracila que substitui a timina (STRYER, 1979, p.595-596).

Ele é responsável pela síntese de proteínas nas células, e possui papel fundamental na replicação do DNA, ou seja, no processo pelo qual a célula faz uma cópia biológica do seu DNA, o que lhe permite a multiplicação, mantendo constante seu material genético, possibilitando o conseqüente crescimento dos organismos multicelulares, assim como a sua reprodução pela formação de gametas (as células reprodutivas como o espermatozóide e óvulo). A replicação do DNA também é necessária para a reprodução dos organismos unicelulares, como bactérias e vírus, que o têm como material genético. Além disso, alguns vírus, chamados de retrovírus, têm como material genético o RNA (STRYER, 1979, passim).

Os carboidratos, como os açúcares, vão ser utilizados para produção de energia, constituição de paredes celulares e muitas outras funções biológicas.

Os aminoácidos são os elementos constituintes das proteínas, sejam elas estruturais, como as que compõem os músculos e os ossos em animais superiores, sejam elas do tipo enzimas, que são as proteínas que vão atuar como operárias na fisiologia celular, nos processos biológicos e na síntese das outras macromoléculas biológicas, como o DNA e o RNA. A função biológica das proteínas é determinada por sua sequiência a qual, por sua vez, será decorrente da seqüência do DNA do gene responsável pela síntese desta proteína pelo organismo.

Os metabólitos secundários, por sua vêz, são produtos do metabolismo secundário produzidos a partir dos metabólitos primários dos organismos e que os beneficiam por atuarem como substâncias tóxicas contra competidores, predadores e parasitas, como bactérias, fungos, plantas, amebas, insetos e vírus. Funcionam também como agentes transportadores de metais no organismo. Os metabólitos secundários estão ainda relacionados à simbiose entre insetos e microrganismos, assim como entre as plantas e microorganismos e atuam no processo de diferenciação celular, pelos qual são produzidos os diferentes tecidos com diferentes funções nos organismos superiores. Elas tem ainda a função de auxiliar na excreção de produtos indesejáveis e atuam na fisiologia celular auxiliando as funções do DNA, servindo ainda como substâncias de reserva para o metabolismo celular. O número e a diversidade de metabólitos secundários existentes são assuntos que têm intrigado os cientistas há muitos anos (DEMAIN, 1992, p.2-3). 
Eles são produzidos a partir de precursores presentes universalmente nos organismos, muito freqüentemente a acetyl-CoA e aminoácidos, e são produzidos de modo mais intenso e variado por microrganismos, em ambientes muito povoados, e por plantas, fungos e animais sésseis como esponjas, onde defesas químicas são mais eficientes do que a fuga. Os primeiros metabólitos secundários foram provavelmente antibióticos produzidos por microorganismos há 3.500 milhões de anos atrás (CAVALIER-SMITH, 1992, p.64).

A indústria farmacêutica tem sido a grande beneficiária do metabolismo secundário por 40 anos, beneficiando-se ainda das técnicas do DNA recombinante (engenharia genética), uma modalidade de biotecnologia, para aumentar a produção do metabolismo secundário nos seus organismos produtores, aumentando assim a sua produtividade. Para se ter uma noção de sua importância comercial basta mencionar que todos os antibióticos utilizados comercialmente, e também muitos medicamentos anti-virais, são metabólitos secundários (DEMAIN, 1992, p.3-23).

Por isso, as moléculas biológicas, tanto os metabólitos primários como os secundários, tem sido objeto de patenteamento nos países mais desenvolvidos, como os EUA, países da União Européia (UE) e Japão (MAGALHÃES, 2005, p.138-147).

\section{A expressão econômica da Biotecnologia}

As moléculas biológicas são a matéria-prima para o desenvolvimento de produtos comerciais pela biotecnologia aplicada na indústria. Existem atualmente nos EUA, 1.300 empresas de biotecnologia. As projeções feitas no início dos anos 80 para o seu crescimento indicavam que, por volta de 1990, a indústria poderia ser avaliada em aproximadamente \$5-7 bilhões. O Relatório Anual da Indústria de Biotecnologia apontou que, somente nos EUA, esta indústria vendeu \$10-12 bilhões em 1993. O dobro das previsões realizadas nos anos 80. Nesse relatório, as vendas nos EUA projetadas para 2035 foram de \$100 bilhões (BURRIL; LEE JR, 1993 apud REAKA-KUDLA; WILSON, D.; WILSON E., 1997, p. 280-281).

Estima-se que nos EUA, 25\% das receitas obtidas com medicamentos, correspondem a medicamentos cujos princípios ativos são extraídos de plantas. Para se ter uma idéia de valores absolutos, este valor correspondeu só em 1990 nos EUA, à quantia de \$ 15.5 bilhões de dólares (PRINCIPE, 1989 apud REID, 1994, p.8). 
Estima-se que, em 1998, a indústria de bioprodutos (produtos resultantes de organismos) vendeu mais de 13 treze bilhões de dólares e aprovou 24 novas biodrogas, o que significa um altíssimo retorno aos investidores (RAYOL, 2000, p.20).

\section{O uso comercial de metabólitos secundários pela Biotecnologia}

A indústria farmacêutica é um dos setores da economia mais beneficiados com o uso dos os recursos da biodiversidade pela biotecnologia. Vários medicamentos contra várias formas de câncer foram desenvolvidos a partir de metabólitos secundários de organismos vegetais e animais como, por exemplo, a vinblastina e vincristina, extraídas da planta Catharanthus roseus e o taxol, extraído da Taxus brevifolia. Alguns medicamentos antimaláricos como artemisina da planta Artemisia annua, vacinas e antibióticos também são obtidos a partir de metabólitos secundários de algumas plantas (BARLOW, 1995, p.668).

Até 1993, o número de empresas farmacêuticas atuando em projetos de bioprospecção de biodiversidade e com extratos biológicos para isolamento de metabólitos primários e secundários, nos países detentores da maior biodiversidade, era avaliado em 21, entre elas a SQUIBB, a MERCK, a CIBA-GEIZY, a MONSANTO, a PFIZER e outras de menor expressão (PRINCIPE, 1989 apud REID, 1994, p.8-15).

As vendas do medicamento veterinário, utilizado para combater parasitas, chamado Invermectin renderam à indústria farmacêutica Merck, o valor de \$ 100 milhões de dólares em vendas em 1991. Seu princípio ativo foi descoberto em um microorganismo de solo do Japão (COUGHLIN, 1993, p.345).

$\mathrm{Na}$ indústria de alimentação, a biotecnologia produz, a partir dos recursos biológicos existentes na biodiversidade, aditivos alimentares, aromatizantes, antioxidantes, corantes naturais e vitaminas. Podemos citar ainda a fermentação de carboidratos, por microorganismos, para a produção do álcool, utilizado inclusive como combustível alternativo. $\mathrm{Na}$ indústria química, existe o desenvolvimento de biopesticidas naturais como as piretrinas extraídas da planta Tanacetum cineraiifolium; azadiractina, potente inseticida extraído da ávore neem, existente na Índia; corantes naturais, bioplásticos degradáveis, como os ácidos polihidroxialcanóicos, biosurfactantes como sabão e detergentes e muitos outros (BARLOW, 1995, p.668).

A biodiversidade marinha se revelou também uma imensa fonte de metabólitos secundários de utilidade humana e valor econômico. As moléculas biológicas produzidas pelos 
organismos que vivem no mar têm recebido, desde o início dos anos 70, uma atenção crescente por parte dos químicos e bioquímicos (IRELAND, 1993, p.1).

Muitos dos metabólitos secundários isolados desde os anos 50, demonstraram ter atividade anti-tumores, como o alcalóide dercitina isolado em 1988, da esponja Dercitus sp., e a aeroplisina isolada em 1970, das esponjas Aplysina aerophoba e Ianthella ardis, que demonstraram ter significante atividade contra a leucemia em pesquisas realizadas em 1989 (IRELAND, 1993, p.1).

Além disso, muitos desses metabólitos têm atividade antiviral. Uma classe de glicolipídios contendo ácido sulfônico, isolados em 1989, das algas azuis microscópicas cultivadas em laboratório, da espécie Lyngbya lagerheimii e Phormidium tenue demonstrou ter atividade inibidora do vírus HIV-1. Polissacarídeos sulfatados isolados em 1988 da alga marrom Laminaria $s p$ demonstraram ter atividade inibidora em vários tipos de vírus, como o herpes simplex e também o HIV (IRELAND, 1993, p.25-28).

Outros metabólitos secundários, sintetizados por organismos marinhos, têm atividade antinflamatória e propriedades analgésicas, como a manoalida, um sesterpeno não esteróidal isolado em 1980 da esponja Luffariella variabilis (IRELAND, 1993, p.25) e pseudopterosinas A e E, membros da família dos diterpenos ribosídeos, com potente atividade anti-inflamatória e analgésica, isolados em 1986 e 1991, dos corais Pseudopterogorgia bipinata e P. elisabethae (IRELAND, 1993, p.24).

Entre 1984 a 1990, extratos e compostos puros de 407 diferentes amostras de esponjas e de um pequeno número de invertebrados marinhos foram pesquisados e uma variedade de compostos conhecidos e muitos ainda desconhecidos até aquele momento, apresentaram ação farmacológica. Desses compostos, 21 isolados de esponjas demonstraram ter poderosa atividade antihelmíntica in vitro confirmada in vivo e um composto, a cucumequinosina, um triterpenóide isolado em 1990 da holotúria, um tipo de animal marinho, Cucumaria echinata, demonstrou ter moderada atividade contra protozoários in vitro (IRELAND, 1993, p.24).

Assim, quanto maior a biodiversidade existente em um país, maior diversidade de moléculas biológicas ele terá e consequentemente maior a probabilidade de nele se descobrirem moléculas biológicas com valor comercial.

Neste sentido devemos destacar que o Brasil é um dos países com maior biodiversidade no mundo e, portanto, com um imenso potencial para o isolamento de moléculas biológicas úteis aos seres humanos e de grande valor comercial. 
Devemos mencionar que estima-se existirem mais de dois milhões de diferentes espécies de plantas, animais e microorganismos em território brasileiro, sendo que a maior parte desta biodiversidade, cerca de $75 \%$ das espécies de organismos da biodiversidade brasileira se encontra na Mata Atlântica e Floresta Amazônica. A diversidade de plantas em nosso país é estimada entre 350000 e 500000 espécies sendo que 55000 foram identificadas até 1998 e somente $8 \%$ destas foram estudadas para se avaliar atividade medicinal de suas moléculas (GUERRA et al apud BRAZ-FILHO, 1999, p.1666).

Várias plantas brasileiras estudadas em instituições públicas de pesquisa apresentaram metabólitos secundários com efeito farmacológico, o que significa que possuem potencial valor comercial.

Somente para exemplificar, podemos citar um metabólito extraído da planta Ouratea hexasperma, que demonstrou ser um potente inibidor de células cancerosas (MOREIRA et al apud BRAZ-FILHO, 1999, p.1666), apresentando, portanto, potencial para ser utilizado como princípio ativo de medicamentos para tratamento de câncer.

Um outro metabólito secundário, extraído das folhas e raízes da planta Harpalyce brasiliana demonstrou ter atividade anti- vírus HIV (FUJIOKA et al apud BRAZ-FILHO, 1999, p.1669)

$\mathrm{Na}$ pesquisa de novas moléculas biológicas com potencial comercial nos organismos constituintes da biodiversidade, avalia-se que, ao não se utilizar os conhecimentos das populações tradicionais locais, para direcionar esta coleta, seja necessário isolar-se 10.000 produtos químicos de origem biológica, para se obter um que tenha potencial para uso comercial (PRINCIPE, 1989 apud REID, 1994, p.8-15). Podemos observar, assim, a enorme importância do conhecimento que as comunidades tradicionais detêm, para se desenvolver produtos comerciais a partir dos componentes da biodiversidade.

Não é possível avaliar com exatidão quantos e quais medicamentos ou outros produtos comerciais desenvolvidos foram ou estão sendo desenvolvidos em outros países a partir de moléculas biológicas de organismos da biodiversidade brasileira. Isto ocorre porque, comumente, principalmente após a celebração da $\mathrm{CDB}$, as indústrias não revelam os organismos, nem sua origem, dos quais foram extraídos os princípios ativos utilizados nestes produtos. 
Quando moléculas biológicas de organismos da biodiversidade de um determinado país são retiradas para fins científicos ou comerciais, sem autorização das autoridades competentes deste país onde são obtidas e sem a contrapartida econômica, se denomina de biopirataria.

\section{O conceito de diversidade biológica (CDB Artigo 2)}

A palavra biodiversidade, sinônimo da expressão diversidade biológica, apareceu há relativamente pouco tempo. Tornou-se conhecida a partir de uma reunião realizada nos Estados Unidos, cujos trabalhos foram publicados em 1988, em um livro organizado pelo ecólogo Edward O. Wilson, da Universidade de Harvard, nos Estados Unidos. O conceito de biodiversidade procura integrar toda a variedade existente de organismos vivos, nos mais diferentes níveis. É difícil expressá-lo com precisão e existem vários enunciados diferentes, de profissionais da área biológica.

Andy Dobson (1996, p.132) define biodiversidade como sendo a "soma de todos os diferentes tipos de organismos que habitam uma região tal como o planeta inteiro, o continente africano, a Bacia Amazônica, ou nossos quintais" (nossa tradução).

Edward O. Wilson a define como sendo "toda a variação baseada em hereditariedade em todos os níveis de organização, dos genes existentes em uma simples população local ou espécies, as espécies que compõem toda ou parte de uma comunidade local, e finalmente, as próprias comunidades que compõem a parte viva dos multivariados ecossistemas existentes no mundo" (REAKA-KUDLA; WILSON, D; WILSON, E, 1997, p.1, nossa tradução).

A Convenção da Diversidade Biológica (CDB), ao invés de utilizar a expressão biodiversidade no seu artigo 2, utilizou a expressão sinônima diversidade biológica, definindo-a como sendo a "variabilidade de organismos vivos de todas as origens, compreendendo, dentre outros, os ecossistemas terrestres, marinhos e outros ecossistemas aquáticos e os complexos ecológicos de que fazem parte; compreendendo ainda a diversidade dentro de espécies, entre espécies e de ecossistemas" ( grifamos).

Como se vê, esta definição chama atenção sobre os diversos níveis existentes na variedade da vida, abrangendo também os ecossistemas, onde os seres vivos em toda sua diversidade vivem, e os complexos ecológicos, que são conjuntos de ecossistemas em uma relação dinâmica entre si. 
Comparando estas definições de biodiversidade podemos observar que Dobson e Wilson excluem os ecossistemas como integrantes da biodiversidade, enquanto a CDB os inclui.

Ocorre que os ecossistemas são constituídos por uma parte biótica, constituída pelos organismos vivos de um ecossistema, e por outra abiótica, correspondente ao meio físico que estes organismos habitam.

Etimologicamente, a palavra bio se origina do grego e significa vida; logo, diversidade biológica significa a diversidade de vida. Ocorre que o componente físico dos ecossistemas não faz parte da vida, apesar de ser o seu suporte, porque não se auto-reproduz, que é a característica básica do fenômeno chamado vida.

Portanto, do ponto de vista técnico biológico, a inclusão de ecossistemas como um todo, o que inclui seu componente abiótico, é um equívoco na definição de diversidade biológica, do texto da $\mathrm{CDB}$, ainda que pela intenção de proteção aos ecossistemas, pois somente o componente biótico dos ecossistemas é vivo.

\section{O conceito de Recursos Biológicos e Recursos Genéticos (CDB, Artigo 2)}

A Convenção sobre a Diversidade Biológica (CDB) define em seu artigo 2:

Recursos biológicos compreendem recursos genéticos, organismos ou partes destes, populações, ou qualquer outro componente biótico de ecossistemas, de real ou potencial utilidade ou valor para a humanidade.

(...)

Recursos genéticos significa material genético de valor real ou potencial

(...)

Material genético significa todo material de origem vegetal, animal, microbiana ou outra que contenha unidades funcionais de hereditariedade. (grifamos)

Os genes são as unidades funcionais de hereditariedade nos animais, nos vegetais e nos microrganismos e são constituídos por um filamento de DNA, em dupla hélice, nos organismos superiores, ou circular, nos microrganismos. Eles estão localizados em estruturas chamadas cromossomos dentro das células dos organismos. Logo, os recursos genéticos são também partes dos organismos.

O importante a destacar aqui, é que quando nos referimos à recursos biológicos, estamos nos referindo aos recursos genéticos e também às demais partes dos organismos 
vivos, inclusive outros metabólitos primários e os secundários, assim como os próprios organismos como um todo.

\section{A substituição da expressão "Recursos Genéticos" por "Recursos Biológicos" para repartição dos benefícios derivados da sua utilização (CBD, artigos 1 e 19.7)}

O artigo 1 define os objetivos da $\mathrm{CDB}$ como sendo:

(...) a conservação da diversidade biológica, a utilização sustentável de seus componentes e a repartição justa e eqüitativa dos benefícios derivados da utilização dos recursos genéticos, mediante, inclusive, o acesso adequado aos recursos genéticos e a transferência adequada de tecnologias pertinentes, levando em conta todos os direitos sobre tais recursos e tecnologias, e mediante financiamento adequado (grifamos).

Ao fazermos uma análise crítica do artigo 1, verificamos que seu texto foi inadequado para os países em desenvolvimento, detentores da maior parte da biodiversidade do planeta, pois os recursos genéticos são constituídos pelos genes, que são as unidades funcionais de hereditariedade dos organismos.

Ocorre que todas as demais moléculas biológicas de grande valor real e potencial, científico e econômico, ficaram excluídas do artigo 1, inclusive outros metabólitos primários, como as enzimas, e todos os metabólitos secundários, que têm sido a maior fonte de matériaprima para a indústria farmacêutica desenvolver novos medicamentos.

Assim, a redação da CDB no artigo 1 e outros, deveria ter utilizado o termo recursos biológicos ao invés de recursos genéticos, pois estes são partes daqueles, de modo que os benefícios derivados da utilização dos recursos biológicos em geral, e não somente dos recursos genéticos, fossem repartidos de forma justa.

Pela mesma razão essa substituição deveria ocorrer no artigo 19.7 da CDB que determina que as Partes devem adotar medidas legislativas, administrativas ou políticas para "compartilhar de forma justa e eqüitativa os resultados da pesquisa e do desenvolvimento de recursos genéticos e os benefícios derivados de sua utilização comercial e de outra natureza com a Parte Contratante provedora desses recursos" (grifamos).

Os países desenvolvidos são os grandes criadores de biotecnologia a qual é intensamente, e com grandes lucros, utilizada pela sua indústria, principalmente a farmacêutica. A 
maioria deles já se vinculou à $\mathrm{CDB}$ por meio da ratificação, como o Reino Unido em 12/06/1993, a Suiça em 21/11/1994, a Alemanha em 21/12/1993, a França em 01/07/1994, a Itália em 15/04/1994 e a Suécia em 16/12/1993, ou por meio da aceitação, como o Japão em 28/05/1993, sendo que tanto a ratificação quanto a aceitação produzem os mesmos efeitos legais, obrigando os países a cumprir as determinaçãos da CDB.

Dos países mais desenvolvidos, somente os EUA não se vincularam ainda, tendo somente assinado a CDB em 14/06/1993, mas não a tendo ratificado até a presente data.

Assim, com o atual texto, estes países desenvolvidos, mesmo que tenham ratificado a $\mathrm{CDB}$, não tem a obrigação de criar meios legais para obrigar as suas indústrias farmacêuticas a repartir os benefícios do uso de qualquer outro recurso biológico que não seja material genético.

\section{A substituição da expressão "Recursos Genéticos" por "Recursos Biológicos" para controle do acesso a estes recursos (CDB, Artigo 15)}

O artigo 15.1 da CDB diz que " Em reconhecimento dos direitos soberanos dos Estados sobre seus recursos naturais, a autoridade para determinar o acesso a recursos genéticos pertence aos governos nacionais e está sujeita à legislação nacional".

Determina também que este acesso seja permitido sem impor restrições contrárias aos objetivos da CDB (artigo 15.2) e considera como parte provedora os países de origem destes recursos ou aqueles que os tenham adquirido em conformidade com as disposições da CDB (artigo 15.3).

Sendo os Estados soberanos sobre seus recursos naturais, esta soberania se estende não somente aos recursos genéticos mas também aos demais recursos biológicos pois estes integram os recursos naturais. Deste modo, a substituição do termo recursos genéticos por recursos biológicos no artigo 15 e seus parágrafos estaria plenamente de acordo com este princípio da soberania dos Estados sobre os seus recursos naturais.

Como desdobramento deste princípio, o artigo 15.5 da CDB estabelece que o acesso aos recursos genéticos deve se sujeitar ao consentimento prévio da Parte provedora dos recursos genéticos, o que permite à ela, estabelecer condições relativas à uma justa repartição dos benefícios pelo uso destes recursos pelas empresas, ou instituições de pesquisa científica, da Parte que os utiliza sendo que a Parte provedora tem ainda o direito de participar nas 
pesquisas científicas com os recursos genéticos acessados, as quais são a base para o desenvolvimento de tecnologias comerciais.

Assim ao se substituir o termo recursos genéticos por recursos biológicos, se estaria dando fundamento legal internacional para que a Parte provedora destes recursos estabelecesse as condições para que as indústrias e institutos de pesquisa de outras Partes acessassem os demais metabólitos, primários ou secundários, e participasse das pesquisas com eles realizada.

\section{A substituição da expressão "Recursos Genéticos" por "Recursos Biológicos" (CDB, artigos 16.1., 9(b), 19.1 E 19.2)}

$\mathrm{O}$ artigo 16.1 disciplina o acesso pelas Partes, à tecnologia, incluíndo a biotecnologia, que utilizar os seus recursos genéticos, assim como disciplina também a transferência desta tecnologia.

O artigo 9(b) trata da conservação ex situ dos componentes da biodiversidade. Ela é definida como sendo "a conservação de componentes da diversidade biológica fora de seus hábitats naturais" (CDB, artigo 2), ou seja, toda aquela feita fora do seu ambiente de ocorrência natural.

Este dispositivo determina que as Partes devem "estabelecer e manter instalações para a conservação $\boldsymbol{e x}$ situ e pesquisa de vegetais, animais e microorganismos, de preferência no país de origem dos recursos genéticos" (grifamos).

Neste caso o uso do termo recursos genéticos ficou inadequado pelo fato do significado da frase ser que os vegetais, animais e microorganismos devem ser, preferencialmente, conservados $\boldsymbol{e x}$ situ no seu próprio país de origem e estes organismos são constituído por inúmeras outras moléculas biológicas além do seu material genético, ainda que se desenvolvam a partir dele.

O termo recursos genéticos deveria ser substituído por recursos biológicos, pois como a própria $\mathrm{CDB}$ define em seu artigo 2, estes compreendem os organismos, como as plantas, animais e microorganismos aos quais se refere o artigo 9(b).

O artigo 19.1 e 19.2 trata da gestão da biotecnologia, dispondo sobre uso dos recursos genéticos por esta modalidade de tecnologia. A biotecnologia é definida pela CDB em seu artigo 2 como sendo "qualquer aplicação tecnológica que utilize sistemas biológicos, organismos vivos, ou seus derivados, para fabricar ou modificar produtos ou processos para utilização específica". 
Pelos mesmos motivos já expostos neste trabalho e para manter uma coerência no texto da CDB como um todo, também nestes dispositivos deveria ocorrer a substituição de termos.

\section{Mecanismos para revisão do texto da CDB}

Qualquer Parte contratante da CDB pode propor emendas ao seu texto (artigo 29.1), que devem ser propostas para serem adotadas em sessão da Conferência das Partes, devendo as demais Partes serem comunicadas pelo Secretariado da CDB pelo menos seis meses antes da sessão na qual a adoção da emenda será proposta (artigo 29.2)

Uma emenda pode ser aprovada por consenso ou, caso as Partes não cheguem à ele, por voto da maioria de dois terços das Partes presentes e votantes nessa sessão, devendo ser submetida pelo Depositário da CDB para ratificação, aceitação ou aprovação das demais partes (artigo 29.3).

O Depositário da CDB e suas eventuais emendas é o Secretário-Geral das Nações Unidas (artigo 41).

Ocorre que os países com maior biodiversidade são os maiores interessados e beneficiados com as alterações, no texto da CDB, neste trabalho propostas, e eles constituem mais de dois terços dos 188 países que são Partes da CDB, o que tornaria viável a aprovação de uma emenda ainda que os países desenvolvidos eventualmente não quissessem a sua adoção para não diminuir os lucros de suas empresas que utilizam a biotecnologia.

\section{Considerações Finais}

O texto da CDB, com a atual redação, determina, o acesso autorizado (artigo15) e a repartição dos benefícios (artigo 1 e 19.7) pelo uso, somente dos recursos genéticos (DNA e RNA em retrovírus), excluindo as demais moléculas biológicas. Dispõe desta mesma maneira sobre a gestão da biotecnologia desenvolvida a partir destes recursos e distribuição dos seus benefícios (artigo 19.1 e 19.2).

Ocorre que outras moléculas biológicas, como vimos neste trabalho, também possuem incomensurável valor, real ou potencial, científico e econômico. Assim, para uma defesa mais efetiva e ampla dos interesses das nações em desenvolvimento, ricas em biodiversidade, há necessidade de se substituir no texto da CDB, em seus arts. 1, 9, 15, 16 e 19, a expressão recursos genéticos por recursos biológicos pelo fato deste termo abranger os recursos 
genéticos e todas as demais moléculas biológicas existentes nos organismos que compõe a biodiversidade.

Com esta alteração, por meio de uma revisão do texto da CDB pelas Partes, através de emendas, esta convenção atingiria de modo mais pleno e eficaz um dos seus principais objetivos e foco das discussões entre os representantes dos países e organizações nãogovernamentais (ONGs) que participaram da ECO-92, que é o estabelecimento de relações mais justas entre os países em desenvolvimento, detentores da maior parte da biodiversidade do planeta, e os países desenvolvidos, detentores da biotecnologia mais avançada, que utilizam esta biodiversidade como fonte de matéria-prima para o desenvolvimento, produção e comercialização de produtos de elevado valor econômico, como medicamentos.

Finalmente, destacamos que o Brasil infelizmente repetiu, em seu ordenamento jurídico, os termos da CDB. A Medida Provisória 2.186-16 de 23 de agosto de 2001, em vigor e em tramitação para sua conversão em lei, dispõe sobre o acesso do patrimônio genético (artigo $1^{\circ}$, inc.I) que que tem o mesmo significado de recursos genéticos, excluindo assim da necessidade de consentimento prévio do governo brasileiro as demais moléculas biológicas de valor econômico real ou potencial.

Do mesmo modo, ela dispõe sobre a "repartição justa eqüitativa dos benefícios derivados da exploração de componente do patrimônio genético" (artigo $1^{\circ}$, inc. III, grifamos) excluindo novamente as demais moléculas biológicas.

Tendo a CDB reconhecido a soberania dos países sobre os seus recursos naturais (CDB, artigo 15.1), os quais abrangem os recursos biológicos, o governo brasileiro poderia dispor, em sua legislação, sobre o acesso e repartição de benefícios gerados pelo uso dos seus recursos biológicos sem ferir as obrigações assumidas com a ratificação da CDB.

Deste modo, mesmo que a MP 2.186-16 tivesse utilizado em seu texto o termo recursos biológicos ao invés de patrimônio genético, ainda assim estaria cumprindo o determinado atualmente pela CDB, e regulamentando os seus artigos 1, 15 e 16 .

Esta medida provisória reproduz, portanto, a lesão dos direitos e interesses nacionais e da sociedade brasileira, consignado no atual texto da CDB, o que esperamos seja sanado no processo de sua eventual conversão em lei. 


\section{Referências Bibliográficas}

BARLOW, B. A et al. Biotechnology,. In: HEYWOOD, V. H.; WATSON, R. T. (orgs). Global biodiversity assessment. Cambridge: Cambridge University Press, 1995, p.671-710.

BRASIL. Decreto $\mathrm{n}^{\circ}$ 2.519, de 16 de março de 1998. Promulga a Convenção sobre Diversidade Biológica, assinada no Rio de Janeiro, em 05 de junho de 1992. Presidência da República Federativa do Brasil. Disponível em < https://www.planalto.gov.br/ccivil_03/decreto/D2519.htm>. Acesso: em 12 ago. 2006.

BRASIL. Medida Provisória n ${ }^{\circ}$ 2.186-16, de 24 de agosto de 2001. Regulamenta o inciso II do $\S 1$ o e o $\S 4$ o do art. 225 da Constituição, os arts. $1^{\circ}, 8^{\circ}$, alínea "j", 10, alínea "c", 15 e 16, alíneas 3 e 4 da Convenção sobre Diversidade Biológica, dispõe sobre o acesso ao patrimônio genético, a proteção e o acesso ao conhecimento tradicional associado, a repartição de benefícios e o acesso à tecnologia e transferência de tecnologia para sua conservação e utilização, e dá outras providências. Presidência da República Federativa do Brasil. Disponível em <https://www.planalto.gov.br/ccivil_03/MPV/2186-16.htm>. Acesso em: 12 ago. 2006.

BRAZ-FILHO, R. Brazilian Phytochemical Diversity: bioorganic compounds produced by secondary metabolism as a source of new scientific development, varied industrial applications and to enhance human health and the quality od life. Pure Applied Chemistry, v.71, n.9, p.1663-1672, 1999.

CAVALIER-SMITH, T. Origins of secondary metabolism. In: CIBA Foundation Symposium 171. Secondary metabolites: their function and evolution. West Sussex: John Wiley \& Sons Ltd., 1992. p.64-87.

COSTA E SILVA, Eugênio. Breves Considerações sobre o Acesso a Recursos Genéticos e Alguns Assuntos Correlatos. Revista da ABPI, n. 28, p.41-51, 1997.

COUGHLIN, Michael D. Using the Merck-INBio Agreement to Clarify the Convention on Biological Diversity. Columbia Journal of Transnational Law. New York, v.31, p.337-375, 1993.

DEMAIN, Arnold L. Microbial secondary metabolism: a new theoretical frontier for academia, a new opportunity for industry. In: CIBA Foundation Symposium 171. Secondary metabolites: their function and evolution. West Sussex: John Wiley \& Sons Ltd., 1992. p.323.

DOBSON, Andrew P. Conservation and biodiversity. New York: Scientific American Library, 1996.

IRELAND, Chris M. et al. Pharmaceutical and Bioactive Natural Products. In: ATTAWAY, David H.; ZABORSKY, Oskar R. (orgs)- Marine Biotechnology I. New York: Plenum Press, 1993, p.1-43. 
MAGALHÃES, Vladimir G. Propriedade Intelectual, Biotecnologia e Biodiversidade. 2005. 262 f. Tese (Doutorado em Direito)- Faculdade de Direito. Universidade de São Paulo. São Paulo.

RAYOL, Alice. Biotecnologia, Ética e Patentes. Revista da ABPI, n. 44, p.20-24, 2000.

REAKA-KUDLA, Marjorie L.; WILSON, Don E.; WILSON, Edward O. Biodiversity II: understan-ding and protecting our biological resources. Washington: Joseph Henry Press, 1997.

REID, Walter V. et al. Prospección da la Biodiversidad. S. José/ Costa Rica: Ed. INBio, 1994.

STRYER, Lubert. Bioquímica. Rio de Janeiro: Reverté, 1979. 